\title{
Marketing and Energy Pricing
}

\author{
Valentyna Novosad \\ The Scientific Company "MAE", Kyiv, Ukraine
}

Email address:

mae2010@meta.ua

\section{To cite this article:}

Valentyna Novosad. Marketing and Energy Pricing. American Journal of Electrical Power and Energy Systems. Vol. 4, No. 3, 2015, pp. 23-28. doi: 10.11648/j.epes.20150403.11

\begin{abstract}
Climate protection, energy efficiency, saving of the fossil fuels is important for our society. Many countries adopted the programs for solving these tasks. These programs include many technical measures for climate protection, saving of fossil fuels and energy efficiency. However not only technical measures, but also economical measures have an impact on performance of these important tasks. In this article I will try to show that application of the basic marketing principles in pricing for energy positively affects the efficiency of the use of energy recourses .For long time the energy companies had a monopoly in the supply of energy to consumers. Because the energy tariffs depend mainly from their overall needs. Taking into account common society tasks, the energy sector needs of new approaches for energy pricing. Principles of marketing can help for energy companies to be more flexible in the dealing with consumers and to establish energy tariffs according to individual conditions of energy supply. Using the general principles of marketing in energy industry you can create a flexible system of prices for energy which will be able to control the scheme of energy consumption, will be able to provide the opportunity for consumers to choose quality, security and reliability of services. Implementation of the main principles of marketing in energy pricing allows to move from the general energy tariff for large groups of consumers to the individual tariff for each consumer. $\mathrm{f}$ schemes and conditions of the supply of energy will give the additional saving of energy. Having opportunities to choose, the consumers will try to optimize their own energy consumption and will choose a time, when he will be able to pay for more modern equipments for its energy supply. So, using the general principles of marketing in energy pricing we will try to solve the problems of middle class population, where payments for energy are essential for theirs budget.
\end{abstract}

Keywords: Economy, Energy, Marketing, Tariffs for Energy

\section{Introduction}

The current pricing system for energy is mainly based on the needs of energy producers and energy transmission organizations." In general what consumers pay for energy depends on where they are".[6,5]. The introduction of some elements of a market economy by creating of the electricity market, the use of hourly electricity pricing and providing of consumers by possibilities of the choice of suppliers who can offer him the different conditions of supply and prices expands opportunities for the development of market relations in energy sector. However now the energy sector doesn't use marketing in its activity.

At the same time yearly electricity tariffs are increasing as a result of increasing the share of expensive but clean energy, as a result increasing the cost of electricity generated from fossil fuels and as a result the significant costs on creation of smart electricity network. Approved programs "A policy framework for the $21^{\text {st }}$ century Grid: Enabling Our Secure
Energy Future" [1],"The Presidents' Climate Action Plane"[3] and "All-of-the-Above-Energy-Strategy"[4] in US and the Directive 2012/27[8] in EU will improve the environmental situation in the country and the reliability of energy supply, but will be need to pay for this. This will be easy not for all consumers. However, the task of energy companies' staff is to satisfy energy needs of all consumers at the appropriate level, do not lose them and collect all money for the delivered energy timely. In such cases marketing comes to the rescue.

\section{Main Part}

I carried out my scientific applied research by the method of analogies.

In order to investigate the possibilities of the use of marketing principles in energy pricing I took the book of a renowned marketer Philip Kotler "Ten Deadly Marketing Sins: Signs and Solutions» [2] and examine the current state of pricing in several energy companies. The main points of 
these studies were

- Segmentation of markets;

-Definition target consumers;

-Definition main competitor companies;

- Create tariff system that reflects the quality and reliability of energy supply;

-Definition main factors influencing on the value of tariffs;

- Influence on the energy tariffs of the market environment PESTO;

- Definition of correlation between commercially reasonable costs and market prices for energy.

It turned out that segmentation of markets for energy companies is very total. Basically consumers divided at prices into four categories (residential, industrial, commercial and transportation). Target consumers are not defined. Accordingly, the prices are determined in general without an individual approach. But there are different consumers within main groups that have various possibilities to use and pay for energy. Also electricity as a commodity has different quality and reliability of supply.

Increase the percentage of the electricity use from nonconventional renewable energy leads to the emergence of new competitors in the traditional producers and suppliers of electricity. In the new economic, social, technological and environmental conditions it is advisable to consider the prospects of energy sector's development in general and specifically for each consumer.

It would be appropriate to consider investment in tariffs for energy of specific consumer and to compare them with the average prices in the group in order that transition to new energy sources occurred in those consumers where it to do is cost-effective and appropriate.

Speaking language of Philip Kotler's book about the current situation in the energy sector, we can be said that this industry has "sins". These "sins" can be summarized as follows.

1. Too large groups for different energy consumers.

2. Insufficient attention to the growing number of competitors

3. Too general approaches to determining of base tariffs

4. No of the flexible system of discounts and bonuses for quality, reliability and the different conditions of energy supplies.

If you use marketing to work with consumers and in the pricing of energy, you can rid of these "sins". Properly conducted market research can be not only self-supporting but can bring substantial profits also.

"An individual approach to each customer." should become by the main slogan of marketing application in the energy sector. Now we'll try to find out in detail how to rid from "sins."

\subsection{New Groups of Energy Consumers}

Philip Kotler writes in his book "Ten Deadly Marketing Sins: Signs and Solutions» that those companies who consider that they are selling their products to everyone, make errors and eventually lose much of their consumers.[2]. To avoid these processes it is necessary to examine in detail of all consumers and to divide them into a lot groups. It is important to identify the category of "target consumers", where energy price will be determined individually.

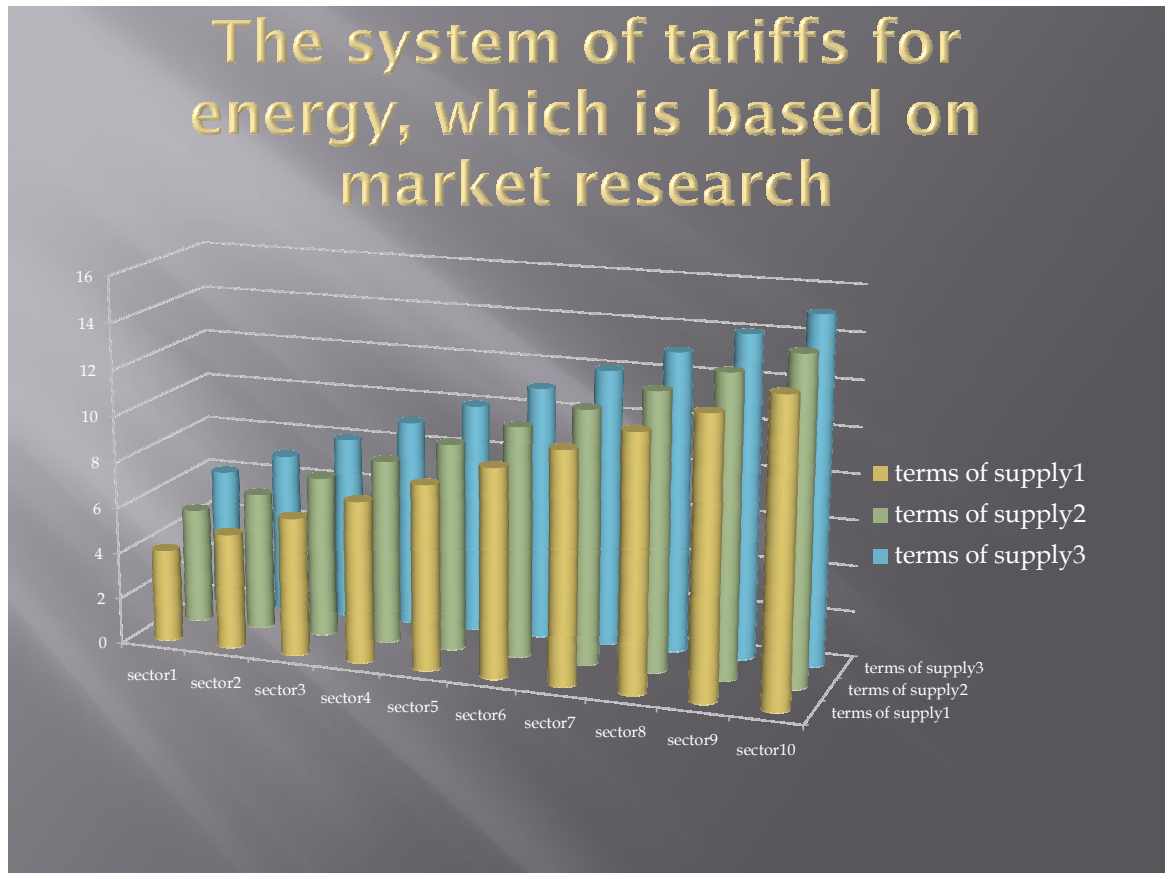

Pic. 1. The system of tariffs for energy, which based on market research.

Before performing this task, it is necessary to determine the criteria that affect significantly on the price of energy supplied to each consumer on the one hand, and the needs of consumers for quality and security of supply as well as their ability to pay for consumed energy the other hand.

It is necessary to recognize as the target consumer those 
consumers which occupy a significant share in total energy consumption and have features in pricing. The list and the number of target consumers should be determined by market research that is performed at least once every 3 years.

It is wishful to have the specific methodology of classification of consumers.

Criteria for the category of "target consumers» can be such:

- The specific share in market consumption

- The critical point of prices, after which the company may lose customers as a result of the use of the alternative energy sources

- Special conditions of energy supply.

All other users can be divided into groups on such criteria:

- Close values of cost.

-Equal opportunities for bill payment.

- The same fate of energy costs in the cost of their products.

- The identical need for security of supply.

- The same transmission charges and losses in network.

- The same location position.

- Possibilities to use of alternative energy sources.

- Other factors that may affect the costs, market prices and the financial capacities of the client.

Such detailed distribution of consumers in the small related groups gives possibility to create a flexible pricing system that could respond timely on changes of the market of energy services.

\subsection{Attention to New Competitors}

The development of wind power, solar power and other alternative energy sources provides additional opportunities for consumers when they choose an energy supply circuit. Therefore it is very important to know main competitors of energy supplies today, in the near future and in the long run in order that energy companies were to able determining their strategy of development, investment policy and prices for separate consumer groups and for target consumers.

With growing of competition between traditional energy sources with the new non-conventional energy sources, strategy of each energy company should be based on favorable quotation of prices, on offers of additional services, improving of quality of customer service and cost-effective advertising services of the company.

The media actively promotes the transition to energy consumption from alternative energy sources. Therefore it is important to promptly identify of main competitors and to have a methodology for determining of the appropriateness of various schemes of energy supplies.

To keep important consumers, energy companies could offer a wide range of additional services and lower prices to the level of appropriateness.

If the energy company loses unprofitable customers with the transition of consumers on other schemes of energy supplies or switching to alternative sources of energy of some consumers is inevitable, this energy company can offer timely service of new equipment and periodically checking of functioning of this equipment.

\subsection{Flexible Approaches to Determining Base Tariffs in New Sectors of Energy Consumption}

A detailed study and establishment of new market segments energy would result in creating of flexible tariffs which are appropriate for each consumer group.

For this the energy companies can detect the maximum number of factors that affect the price of energy supply of the target users or the group of identical customers and try to use them to create a balance of interests between suppliers and consumers

Thus, the most significant impact on energy prices makes the cost of fuel resources. Some target consumers is connected to the nearest power stations. The basic cost of electricity for them can depend directly from the cost of electricity produced in a particular power station as well as from fuel costs, which it uses. It is can use when considering of the energy tariff for this category of consumers.

Another important influence on the energy tariff has the cost of purchased energy, Companies that have their own energy production the ratio between purchased energy and energy of own production can be adjusted depending on the prices of purchased energy and production cost of own energy.

Consumers can be divided into consumers with stable levels of consumption and consumers for which Energy Company should to buy additional energy during peak times. The company may offer to consumers for which it buys expensive electricity in peak times the use of hourly tariffs in order to change the regime their activities.

The losses in the network can be decisive in shaping of the basic tariffs for a particular group of consumers. This factor together with the cost of repair and maintenance of equipment can determine the feasibility of the rapid transition of customers to consumption of energy from alternative sources.

The cost of repair and maintenance of equipment also constitute one of the main factors influencing the basic tariffs of certain groups of consumers. It would be useful that tariffs for electricity for the separate consumer were calculated depending from the costs of repair and maintenance of equipment and losses in the network which were spent for this consumer.

Perhaps the changing of circuit power supply consumers with the greatest needs in the cost of repairing old equipment, can give for Energy Company the additional savings of money.

Investment component is another one from the important factors influencing on the energy tariff. The equipment of major energy companies requires significant investments in modernization. Adopted by the $21 \mathrm{st}$ Century network program involves the creation of intelligent electricity network.[1]. This requires significant investment and time. Maybe when considering individual investments for each user or small group of consumers there are those who can pay significant investments faster and there are those who, due to unavailability of the money would will to postpone the 
project of modernization electrical networks involved in their energy supply for awhile.

In establishing the basic energy tariffs for specific groups you cannot ignore the influence of current political, economic, social, technological, ecological environment (short- PESTE).

Political decisions, the development of individual regions, economic opportunities to invest of some areas, the level of the life of individual social groups of consumers and their capacity of payment of bills for the consumed energy, the current state of energy objects and environmental aspects can significantly affect a basic level of energy tariffs.

Modern energy consumers increasingly buy own energy equipment. In these cases the point of division between the energy company and the consumer becomes closer towards to the energy company. These consumers pretend to a substantial discount to pay for energy, because they are responsible for maintenance and repair of their own energy equipment, which is involved in supplying energy to them.

Some forms of basic energy tariffs may encourage consumers to increase production, by reducing the total payment with increasing of energy consumption for production needs.

Overall economic position in society and of individual consumers significantly affects their behavior. Energy companies should anticipate and respond promptly on risk factors of non-payments.

Also the social element of modern society is important factor influencing on the pricing. Setting energy tariffs for householders, it is need always to consider the possibility of population to pay bills for consumed energy. Not all value of tariffs and not always correspond with possibilities to pay bills for consumed energy. In the same time, not all the population is need of social protection. A successful system of tariffs for energy even for this group may adjust relationship between the Energy Company and customers so that the losses will be minimal.

The difference in costs of energy companies with the modern high-tech equipment and energy companies with the old energy equipment is significant. This factor also affects the value of the tariff for energy.

An environmental factor of modern market society also brings changes for energy tariffs. Society wins setting the lower tariffs for clean energy and cleaner production.Now "the use of feet-in- tariffs (FIT) is gaining popularity in the United States as a policy option for encouraging renewable energy development".[7]. Consumers of environmentally friendly production have the right to a "green energy tariffs", which will be lower than the level of energy tariffs for polluting industries. These tariffs will stimulate to increase clean production, and others, to closing the harmful productions. However, such methods establishing incentives to improve environmental should use carefully and consider all other factors.

Establishment of a system of basic tariffs requires control over the cost of energy for individual customers or groups of customers with similar conditions of supply. It is necessary to take into account the personal costs related with this consumer (or group of customers). Determining of correlation between costs for individual consumers (or consumer groups) and their market tariffs for energy will allow identifying consumers for which is need to change the scheme of energy supplying or to do switching to alternative energy sources.

Marketing research can identify other important factors influencing on the value of the base tariffs for energy which can to change the tariff policy of Energy Company, the strategy of its development as well as to impact on investment policy.

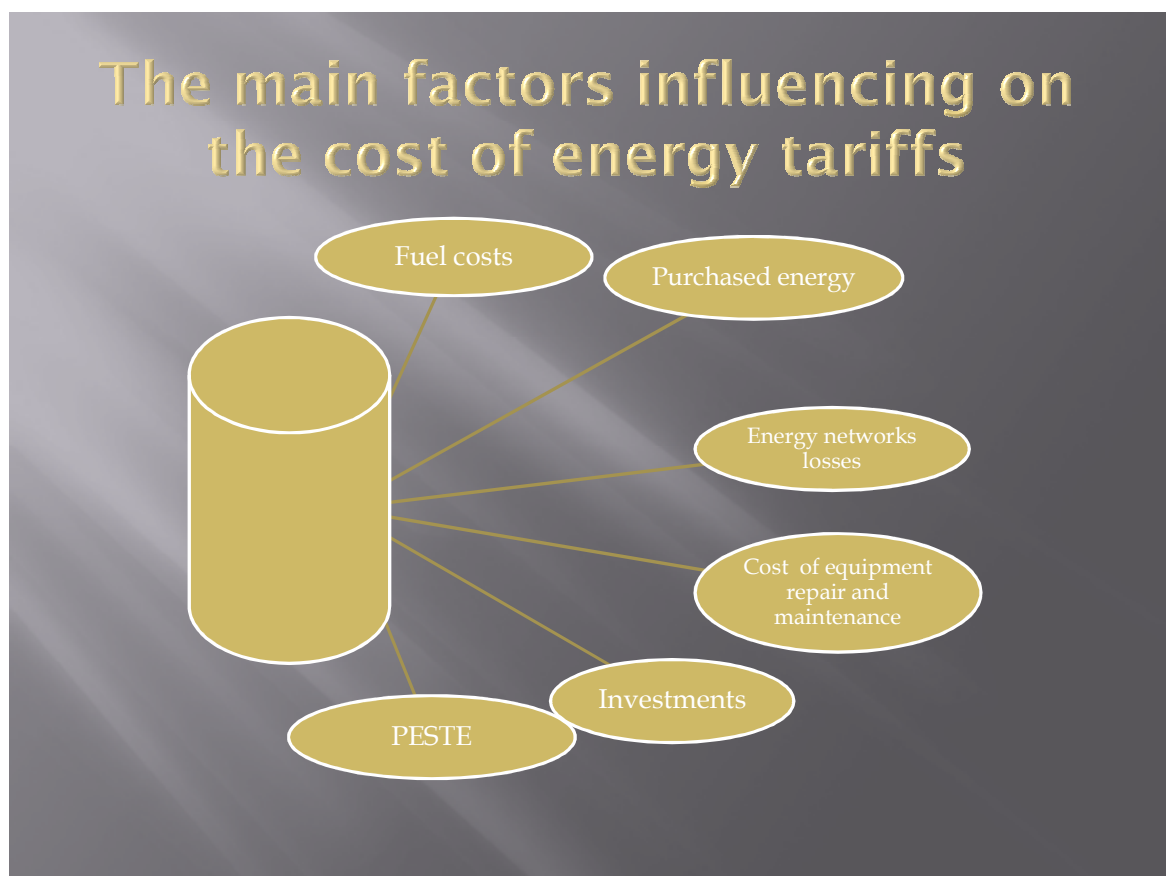

Pic. 2. The main factors influencing on the cost of energy tariffs. 


\subsection{Setting of the Multidimensional System of Tariffs for Energy that Satisfy the Needs of Energy Companies, Consumers and Meets the Needs of the Whole Society}

The system of energy tariffs should include also stimulating discounts and bonuses. These discounts and bonuses should be not only for time zones but also for quality, reliability, security, seasonality, using of new devices for keeping energy, smart meters, investment in improving of security the energy network and other factors that influence on the price. An example is the setting of discounts and bonuses for the use of electricity at different times of the day and the system of discounts for the use of smart meters that are in some US states and in Canada.[10,11]

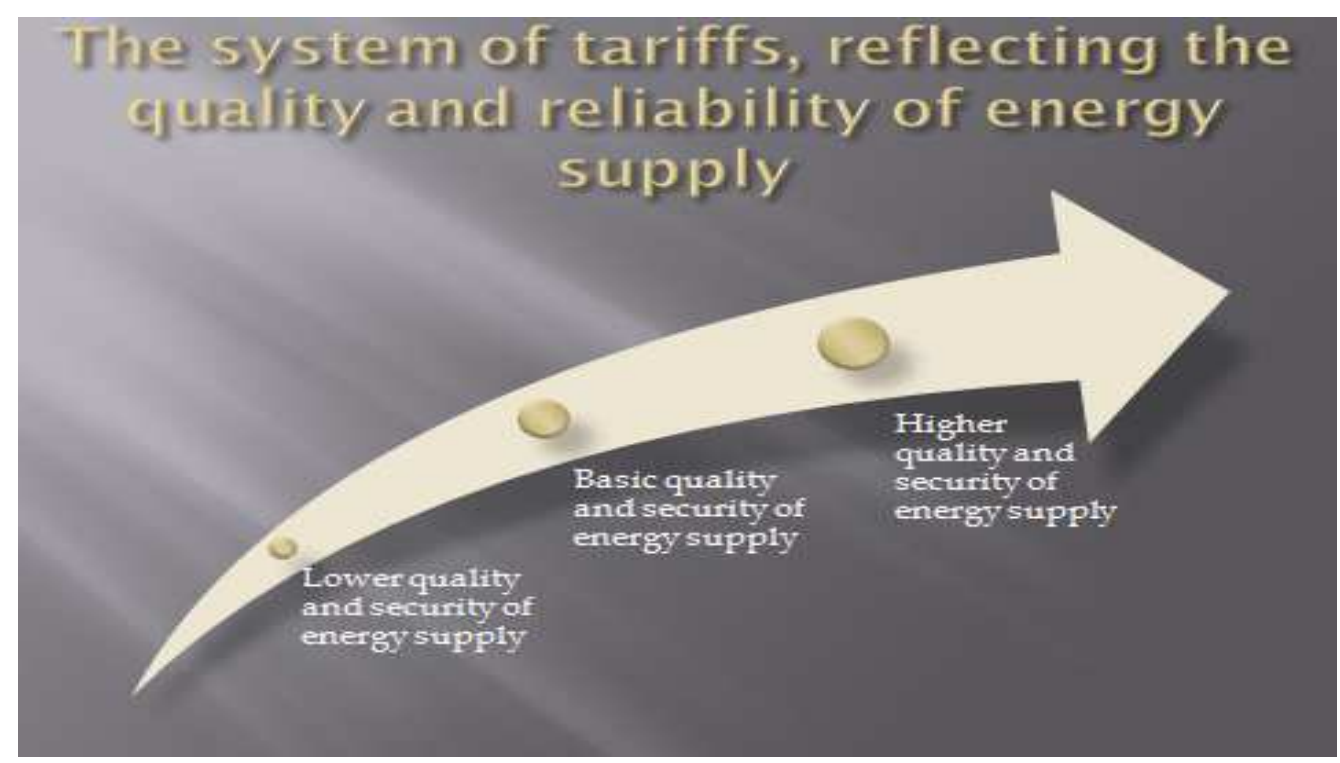

Pic. 3. The system of tariffs reflecting the quality and reliability of energy supply[9].

Methodology of tariff setting for energy may to foresee the creating of different tariff levels depending on the reliability, security and quality of energy supply as is done in the global business: for basic quality, security and reliability of energy supply - the base price, for lower quality, security and reliability of energy supply - the lower price, for higher quality, security and reliability of energy supply - the higher price.

It is necessary to take into account the advice of experienced staff from the energy sales department. If a company's personnel policy was correct, the implementation of multidimensional system of tariffs for energy will bring additional revenue and success for the company.

\section{Conclusions}

Marketing research in the field of energy and their using in energy pricing, lead to better relations between energy companies and consumers, will give saving of energy and money for the energy companies and will provide new opportunities for selecting by consumers of modes of electricity consumption, of quality and reliability of supplies and opportunities for savings of own funds by consumers.

The formation of the system of energy tariffs for the each energy company should be based on the marketing research and to include:

- Individual tariffs for consumers with special conditions of securing them by energy.
-Enough consumer groups that have the same conditions of energy supply and the same possibilities to pay the bills.

-Enough different types of tariffs for different conditions of supplies and consumption so that consumers can choose them according to their needs.

\section{References}

[1] Report "A policy framework for the 21st century Grid: Enabling Our Secure Energy Future". Executive office of the President, White House, Washington, June 2011.

[2] Philip Kotler "Ten Deadly Marketing Sins: Signs and Solutions», ISBN; 978-0-471-65022-5, Wiley-160page, April, 2004

[3] The President's Climate Action Plan, White house, Office of the President, June, 2013

[4] All-of-the-Above-Energy Strategy, White House, Office of President, March, 15, 2015

[5] Independent Statistic \& Analysis, (EIA), Electric power monthly, www.eia/electricity /monthly

[6] Utility Dive News, www.utilitydive.com/news/5-chartsexplain-us-electricity -prices/378054

[7] Katryn Cory "State Clean Energy Policies Analysis (SCEPA)Project:An analysis of Renewable Energy Feed-inTariffs in the United States", National Renewable Energy Laboratory. Technical report NPEL/TR-6A2-45551.Revised June-2009, www.nrel.gov./doc/fy09osti/45551.pdf 
[8] The Directive 2012/27EU of the European Parliament and of the Council of 25 October 2012 on energy effiency, Official Journal of the European Union-L/315/e

[9] Valentyna Novosad "Comparison of the pricing system for heat energy tariffs in Ukraine and the European Union"Sworld, E-Journal ISSN-2227-6920, Vol j21317, November 2013
[10] Prices \& trends, www.energy.gov./public-services/energyeconomy/prices-trends

[11] Smart meters and time of use prices. www.energy.gov.on.ca/en/smart-meters. 